\title{
Protective effect of gallic acid derivatives from the freshwater green alga Spirogyra sp. against ultraviolet B-induced apoptosis through reactive oxygen species clearance in human keratinocytes and zebrafish
}

\author{
Lei Wang ${ }^{1}$, BoMi Ryu ${ }^{1}$, Won-Suk Kim ${ }^{2}$, Gwang Hoon Kim ${ }^{3}$ and You-Jin Jeon ${ }^{1, *}$ \\ ${ }^{1}$ Department of Marine Life Sciences, Jeju National University, Jeju 63243, Korea \\ ${ }^{2}$ Major in Pharaceutical Engineering Division of Bio-Industry, Silla University, Busan 46958, Korea \\ ${ }^{3}$ Department of Biology, Kongju National University, Kongju 32588, Korea
}

In the present study, we enhanced the phenolic content of 70\% ethanol extracts of Spirogyra sp. (SPE, $260.47 \pm 5.21$ gallic acid equivalent [GAE] $\mathrm{mg} \mathrm{g}^{-1}$ ), 2.97 times to $774.24 \pm 2.61 \mathrm{GAE} \mathrm{mg} \mathrm{g}^{-1}$ in the ethyl acetate fraction of SPE (SPEE). SPEE was evaluated for its antiradical activity in online high-performance liquid chromatography-ABTS analysis, and the peaks with the highest antiradical activities were identified as gallic acid derivatives containing gallic acid, methyl gallate, and ethyl gallate. Isolation of ethyl gallate from Spirogyra sp. was performed for the first time in this study. In ultraviolet B (UVB)-irradiated keratinocytes (HaCaT cells), SPEE improved cell viability by $8.22 \%$, and $23.33 \%$ and reduced accumulation of cells in the sub- $\mathrm{G}_{1}$ phase by $20.53 \%$, and $32.11 \%$ at the concentrations of 50 and $100 \mu \mathrm{g} \mathrm{mL}^{-1}$, respectively. Furthermore, SPEE (50 and $100 \mu \mathrm{gLL}^{-1}$ ) reduced reactive oxygen species generation in UVB-irradiated zebrafish by $66.67 \%$ and $77.78 \%$. This study suggests a protective activity of gallic acid and its derivatives from Spirogyra sp. against UVB-induced stress responses in both in vitro and in vivo models, suggesting a potential use of SPEE in photoprotection.

Key Words: apoptosis; gallic acid derivatives; phenolic content; reactive oxygen species; Spirogyra sp.; ultraviolet B

\begin{abstract}
Abbreviations: AAPH, 2,2'-azobis(2-amidinopropane) hydrochloride; ABTS, 2,2'-azino-bis(3-ethylbenzothiazoline6-sulphonic acid); $\mathrm{ACN}$, acetonitrile; $\mathrm{CPC}$, preparative centrifugal partition chromatography; $\mathrm{DCFH}_{2}, 2,7$-dichlorodihydrofluorescein; DCFH-DA, 2',7'-dichlorodihydroflurescin diacetate; DMEM, Dulbecco's modified Eagle medium; dpf, days post-fertilization; DW, distilled water; FBS, fetal bovine serum; GAE, gallic acid equivalent; HPLC, high-performance liquid chromatography; LDH, lactate dehydrogenase; MTT, 3-(4-5-dimethyl-2yl)-2-5-diphynyltetrasolium bromide; NMR, nuclear magnetic resonance; PBS, phosphate buffered saline; ROS, reactive oxygen species; SPE, 70\% ethanol extracts of Spirogyra sp.; SPEC, chloroform fraction of SPE; SPEE, ethyl acetate fraction of SPE; SPEH, hexane fraction of SPE; SPEW, water fraction of SPE; UV, ultraviolet
\end{abstract} terms of the Creative Commons Attribution Non-Commercial License (http://creativecommons.org/licenses/by-nc/3.0/) which permits unrestricted non-commercial use, distribution, and reproduction in any medium, provided the original work is properly cited.
Received August 4, 2017, Accepted November 29, 2017

*Corresponding Author

E-mail: youjinj@jejunu.ac.kr

Tel: +82-64-754-3475, Fax: +82-64-756-3493 


\section{INTRODUCTION}

Although ultraviolet (UV) is essential for human life, it can impair the ability of basal keratinocytes to maintain skin homeostasis against UV-induced damage, by which can be a major contributor in the development of skin cancers (Kong et al. 2015). Ultraviolet B (UVB), a type of UV in the wavelength ranging from $280 \mathrm{~nm}$ to $315 \mathrm{~nm}$, has been studied in the epidermal sun-burn of keratinocytes that are destined to DNA damage and apoptosis after sun exposure. Although humans are exposed to UVA 10 to 100 folds more than UVB, UVB is known to be 1,280 folds more effective at inducing erythema, thus more than $90 \%$ of erythema induced by UV irradiation is attributed to UVB (Ryu et al. 2015). Furthermore, due to the ozone layer becoming thinner from anthropogenic activities, an excessive amount of UVB in the biosphere is being irradiated (Liu et al. 2015). UVB stimulates generation of reactive oxygen species (ROS), including superoxide anion radical $\left(\mathrm{O}^{2-}\right)$, hydrogen peroxide $\left(\mathrm{H}_{2} \mathrm{O}_{2}\right)$, hydroxyl radical (HO-), and singlet oxygen $\left({ }^{1} \mathrm{O}_{2}\right)$ that may result in the destruction of keratinocytes through cellular damage and apoptosis (Kulms and Schwarz 2002, Rezvani et al. 2006, Kim et al. 2007, Gill and Tuteja 2010, Oh et al. 2016, Sanjeewa et al. 2016).

Many studies have been conducted to find the bioactive extracts or active ingredients derived from natural sources, particularly having polyphenol structure including hydroxyl groups on aromatic rings, which can modulate the generation of UVB induced-ROS (Samarakoon et al. 2013, Kim et al. 2014, Farooqi et al. 2015, Lee et al. 2015b, 2015c, 2015d, Alves et al. 2016, Fernando et al. 2017a, 2017b).

Spirogyra sp. is the freshwater green alga used as a biosorbent to remove heavy metal ions from wastewaters (Gupta et al. 2001, Bishnoi et al. 2005, Gupta et al. 2006, Mohan et al. 2007, Gupta and Rastogi 2008). Spirogyra sp. has recently been known for its pharmacological activities as an anti-hypertension, resulted from its isolated gallic acid (Kang et al. 2015), as well as its potential as a bioenergy producing resource (Eshaq et al. 2010, Ramaraj et al. 2015). Our previous study investigated the protective effect of Spirogyra sp. against 2,2'-azobis(2amidinopropane) hydrochloride (AAPH)-induced lipid peroxidation in zebrafish (Lee et al. 2015a). However, the protective effects of Spirogyra sp. against UVB-induced apoptosis have not yet been assessed.

Zebrafish (Danio rerio) has been increasingly used as an in vivo animal model for assessment of drug efficacy, toxicity and safety (Hwang et al. 2016). This is due to its short life span, comparatively small size, and similarity to mammals (Ko et al. 2011). Zebrafish have previously been used in several studies as an in vivo model for UV protective research (Dong et al. 2007, Ko et al. 2011, Yang et al. 2012). Hence, we selected zebrafish as an in vivo model to investigate the UVB protective effect of Spirogyra sp. in this study.

In this study, we have evaluated the phenolic content of $70 \%$ ethanol extract of Spirogyra sp. by three stage serial fractionations and examined the effects of gallic acid derivatives of Spirogyra sp. against UVB-induced ROS production and apoptosis in in vitro $\mathrm{HaCaT}$ cells and in vivo zebrafish. Furthermore, we isolated the bioactive compounds from the gallic acid derivatives by preparative centrifugal partition chromatography (CPC). The purpose of the present work was to assess the potential of the gallic acid derivatives of Spirogyra sp. in prevention of UVB-induced skin damage and to isolate its bioactive compounds.

\section{MATERIALS AND METHODS}

\section{Chemicals and reagents}

The fluorescent probe $2^{\prime}, 7^{\prime}$-dichlorodihydroflurescin diacetate (DCFH-DA) and 3-(4-5-dimethyl-2yl)-2-5-diphynyltetrasolium bromide (MTT), dimethyl sulfoxide and phosphate buffered saline (PBS), standard gallic acid, and 2,2'-azino-bis(3-ethylbenzothiazoline-6-sulphonic acid) (ABTS) were purchased from Sigma Co. (St. Louis, MO, USA). Online high-performance liquid chromatography (HPLC)-grade acetonitrile (ACN) was purchased from Burdick \& Jackson (Muskegon, MI, USA). The Dulbecco's modified Eagle medium (DMEM), penicillin / streptomycin, and fetal bovine serum (FBS) were purchased from Sigma Co. The solvents used for CPC were purchased from Fluka Co. (Buchs, Switzerland). All other chemicals used in this study were of analytical grade.

\section{Fractionation and characterization of $70 \%$ etha- nol extracts of Spirogyra sp. (SPE)}

Fractionation. Spirogyra sp. was collected in the spring season, in January 2014, from the shallow ponds of Kongju, South Korea $\left(36^{\circ} 20^{\prime} 34^{\prime \prime} \mathrm{N}, 127^{\circ} 12^{\prime} 28^{\prime \prime}\right.$ E). Lyophilized algae powder ( $10 \mathrm{~g}$ ) was extracted by $70 \%$ ethanol (1 L) under continuous shaking at $120 \mathrm{rpm}$ for $24 \mathrm{~h}$ at $25^{\circ} \mathrm{C}$ without light and subsequently filtered through Whatman No. 4 filter paper. The extracts were concentrated 
using rotary evaporator at a low pressure and temperature less than $37^{\circ} \mathrm{C}$. Finally, we obtained the $70 \%$ ethanol crude extract of Spirogyra sp. that is referred to as SPE. SPE was further fractionated by different polarity organic solvents that include hexane, chloroform, and ethyl acetate. The hexane, chloroform, ethyl acetate, and water fractions of SPE were named as SPEH, SPEC, SPEE, and SPEW, respectively.

Phenolic content measurement. The total phenolic contents of SPE and its fractions were determined based on the method described by Chandler and Dodds (1983). Gallic acid was used as the reference phenolic compound to construct the standard curve and calculate the phenolic content of samples.

Determination of ABTS radical scavenging activity of SPEE by HPLC system. The ABTS radical scavenging activity of SPEE was analyzed by online HPLC system (Lee et al. 2015a). A concentration of $2 \mathrm{mM}$ ABTS radical solvent containing $2.5 \mathrm{mM}$ potassium persulfate was prepared and incubated with samples for $24 \mathrm{~h}$ for radical stabilization. HPLC system equipped with binary Waters 515 pump, Waters 2489 UV/Vis and 2998 photodiode array detector, and Waters 2707 auto-sampler, coupled with the interface $\mathrm{ABTS}^{+}$radical analyzer (Waters, Mailford, MA, USA) was used. A volume of $10 \mu \mathrm{L}$ SPEE ( $5 \mathrm{mg} \mathrm{mL}^{-1}$, dissolved in methanol) were injected to an Atlantis T3 $3 \mu \mathrm{m} 3.0 \times 150 \mathrm{~mm}$ column (Waters) and run at $0.3 \mathrm{~mL}$ $\mathrm{min}^{-1}$ flow rate using a gradient of ACN and distilled water (DW) solvent system: 0-10 min, $0 \% \mathrm{ACN}$ and $100 \% \mathrm{DW}$; 10-30 min, 25\% ACN and 75\% DW; 30-80 min, 50\% ACN and $50 \%$ DW; $80-90 \mathrm{~min}, 100 \%$ ACN and $0 \%$ DW; $90-110$ min, $100 \%$ ACN and $0 \%$ DW. Wavelength was at $220 \mathrm{~nm}$. SPEE was eluted through the column, and the elution was reacted with ABTS radical in the reaction coil at $40^{\circ} \mathrm{C}$. The absorbance of the reaction mixture was measured as the negative peak by UV / Vis detector at a wavelength of 680 nm.

Separation and identification bioactive compounds of SPEE. The active compounds from SPEE were separated in CPC chromatography (Sanki Engineering, Tokyo, Japan), and the target fraction was further purified by HPLC following above the methods until its amount and purity were enough for structural identification. The structure of target compound was identified by the spectroscopic data provided by the nuclear magnetic resonance (NMR) spectroscopy. The ${ }^{1} \mathrm{H}$-NMR and ${ }^{13} \mathrm{C}-\mathrm{NMR}$ spectrums were recorded on JEOL DELTA-400 $(400 \mathrm{~Hz})$ spectrometer (Jeol, Tokyo, Japan). The chemical shifts of the spectrums were reported as $\delta$ relative to tetramethylsilane as an internal standard.

\section{In vitro analyses}

Cell culture and UVB irradiation. Human keratinocytes (HaCaT cells) were purchased from Korean Cell Line Bank. The HaCaT cells were maintained in DMEM supplemented with $10 \%$ heat-inactivated FBS, streptomycin $\left(100 \mu \mathrm{gLL}^{-1}\right)$, and penicillin $\left(100\right.$ unit $\left.\mathrm{mL}^{-1}\right)$ at $37^{\circ} \mathrm{C}$ with $5 \% \mathrm{CO}_{2}$. Cells were sub-cultured at 3 day intervals and seeded at a density of $1.0 \times 10^{5}$ cells per well in a 24 -well plate. UVB irradiation was imposed using a UVB meter (UV Lamp, VL-6LM; Vilber Lourmat, Torcy, France) with a fluorescent bulb emitting 280-320 nm wavelengths with a peak at $313 \mathrm{~nm}$. HaCaT cells were irradiated at a dose of $30 \mathrm{~mJ} \mathrm{~cm}^{-2}$ of UVB in PBS (Heo et al. 2010). Cells were subsequently incubated until analysis.

Determination of cell viability and apoptotic cell death analysis. For analyzing the protective effect of SPEE against UVB-induced cell damage, HaCaT cells were treated with different concentrations of $\operatorname{SPEE}(25,50$, and $100 \mu \mathrm{g} \mathrm{mL}-1)$ for $2 \mathrm{~h}$ at $37^{\circ} \mathrm{C}$. Cells were then exposed to 30

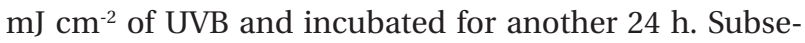
quently, cell damage and proliferation were assessed by lactate dehydrogenase (LDH) release assay and MTT assay respectively as described previously (Kang et al. 2014).

The protective effect of SPEE against apoptosis was evaluated by nuclear staining and cell cycle analysis as per manufacturer's protocol (Wijesinghe et al. 2013). The stained cells were observed using a fluorescence microscope (Olympus, Tokyo, Japan) to examine apoptotic body formation. Histograms of cell distribution in the different cell cycle phases were analyzed by the Quest and Mod-Fit (BD Bioscience, San Jose, CA, USA). The anti-apoptotic activity of SPEE was evaluated by assessing the change in the percentage of cell distribution at sub- $\mathrm{G}_{1}$ phase.

Determination of intracellular ROS generation induced by UVB irradiation in HaCaT cells. Subsequent to 30 min incubation with SPEE, cells were labeled with DCFH-DA (500 $\left.\mu \mathrm{g} \mathrm{mL}^{-1}\right)$ for $30 \mathrm{~min}$ and exposed to UVB irradiation $\left(30 \mathrm{~mJ}^{-2}\right)$. Fluorescent intensity was determined at an excitation wavelength of $485 \mathrm{~nm}$ and an emission wavelength of $535 \mathrm{~nm}$, using a fluorescent microplate reader (BioTek, Synergy HT, Wonooski, VT, USA).

\section{In vivo analyses}

Origin and maintenance of parental zebrafish. The adult zebrafish were purchased from a commercial dealer (Seoul aquarium, Korea). Fish were separately kept in $3 \mathrm{~L}$ acrylic tanks at $28.5^{\circ} \mathrm{C}$, with a $14: 10 \mathrm{~h}$ light : dark cycle. Zebrafish were fed 3 times day ${ }^{1}, 6$ days wk $^{-1}$, with Tetra- 


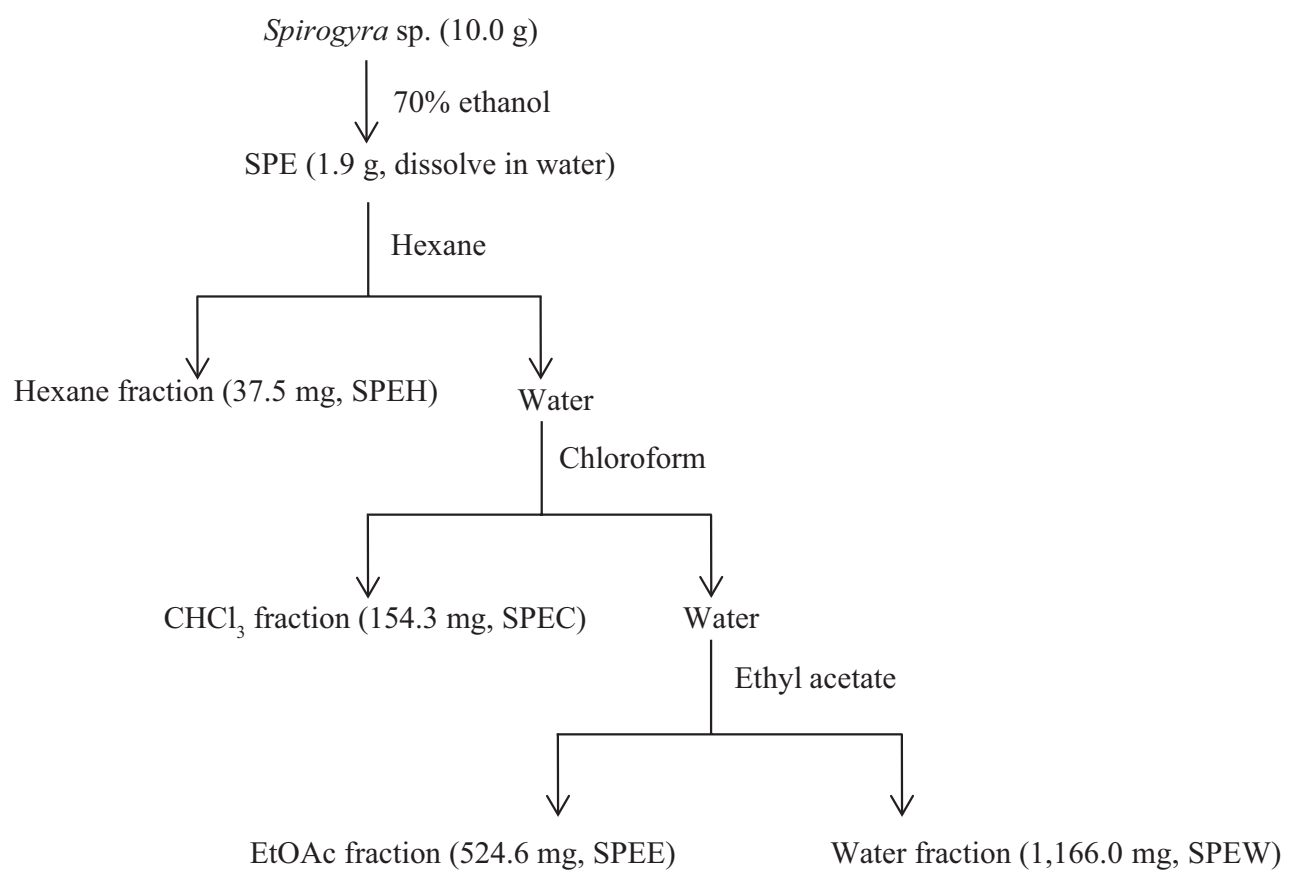

Fig. 1. Extraction and fractionation scheme of $70 \%$ ethanol extracts of Spirogyra sp. (SPE) was fractioned and four fractions (hexane fraction of SPE [SPEH], chloroform fraction of SPE [SPEC], ethyl acetate fraction of SPE [SPEE], and water fraction of SPE [SPEW]) were obtained.

min flake food supplemented with live brine shrimps. Embryos were obtained from natural spawning that was induced in the morning by turning on the light. Collections of embryos were completed within $30 \mathrm{~min}$.

Determination of UVB protective effect of SPEE against UVB-irradiation in vivo zebrafish. The 2-days post-fertilization (dpf) embryos were used to evaluate the UVB protective effect of SPEE in this study. Embryos were collected in 12-well plates (10 embryos per well) containing $2 \mathrm{~mL}$ embryo medium, and subjected to SPEE with a final concentration of 25,50 , and $100 \mu \mathrm{gL}^{-1}$ for $1 \mathrm{~h}$. The embryos were then washed with fresh media and exposed to $50 \mathrm{~mJ} \mathrm{~cm}^{-2}$ UVB per individual (Heo et al. 2009). The exposed embryos to UVB were transferred into a 24-well plate and labeled with DCFH-DA (400 $\left.\mu \mathrm{g} \mathrm{mL}^{-1}\right)$ for $1 \mathrm{~h}$. The embryos were washed twice with fresh media and anesthetized using phenoxyethanol prior to visualization (Ko et al. 2011). The anesthetized embryos were photographed under a microscope equipped with Cool SNAPPro color digital camera (Olympus). Fluorescence intensities were quantified by an image J program.

\section{Statistical analysis}

All the experiments were performed in triplicate. The data were expressed as the mean \pm standard error (SE), and one-way ANOVA test (using Statistical Product and
Service Solutions 11.5 statistical software) was used to statistically compare the mean values of each treatment. Significant differences between the means of parameters were determined by Duncan's multiple range tests, $\mathrm{p}<$ 0.05 and $p<0.01$ were considered as significantly different.

\section{RESULTS}

\section{Phenolic content for serial fractions of SPE}

The 70\% ethanol extract of Spirogyra sp. was prepared and $1.92 \mathrm{~g}$ of it was used for serial fractionations using solvents of increasing polarity (Fig. 1). Serial fractionation yielded various quantities, with hexane fraction being $37.50 \mathrm{mg}$, followed by a chloroform fraction, an ethyl acetate fraction, and a water fraction yielding 154.30, 524.61, and 1,166.00 mg of residue, respectively (Table 1).

Each fraction was assessed for its total phenolic content. As shown in Table 1, total phenolic contents of the different fractions from serial fractionations ranged from $70.74 \pm 2.61$ to $774.42 \pm 2.61 \mathrm{mg} \mathrm{g}^{-1}$ gallic acid equivalent (GAE). Through serial fractionations, phenolic content of SPE (260.47 $\left.\pm 5.21 \mathrm{mg} \mathrm{mL}^{-1} \mathrm{GAE}\right)$ enhanced 2.97 times to $774.42 \pm 2.61 \mathrm{mg} \mathrm{g}^{-1}$ GAE of SPEE (Table 1). 

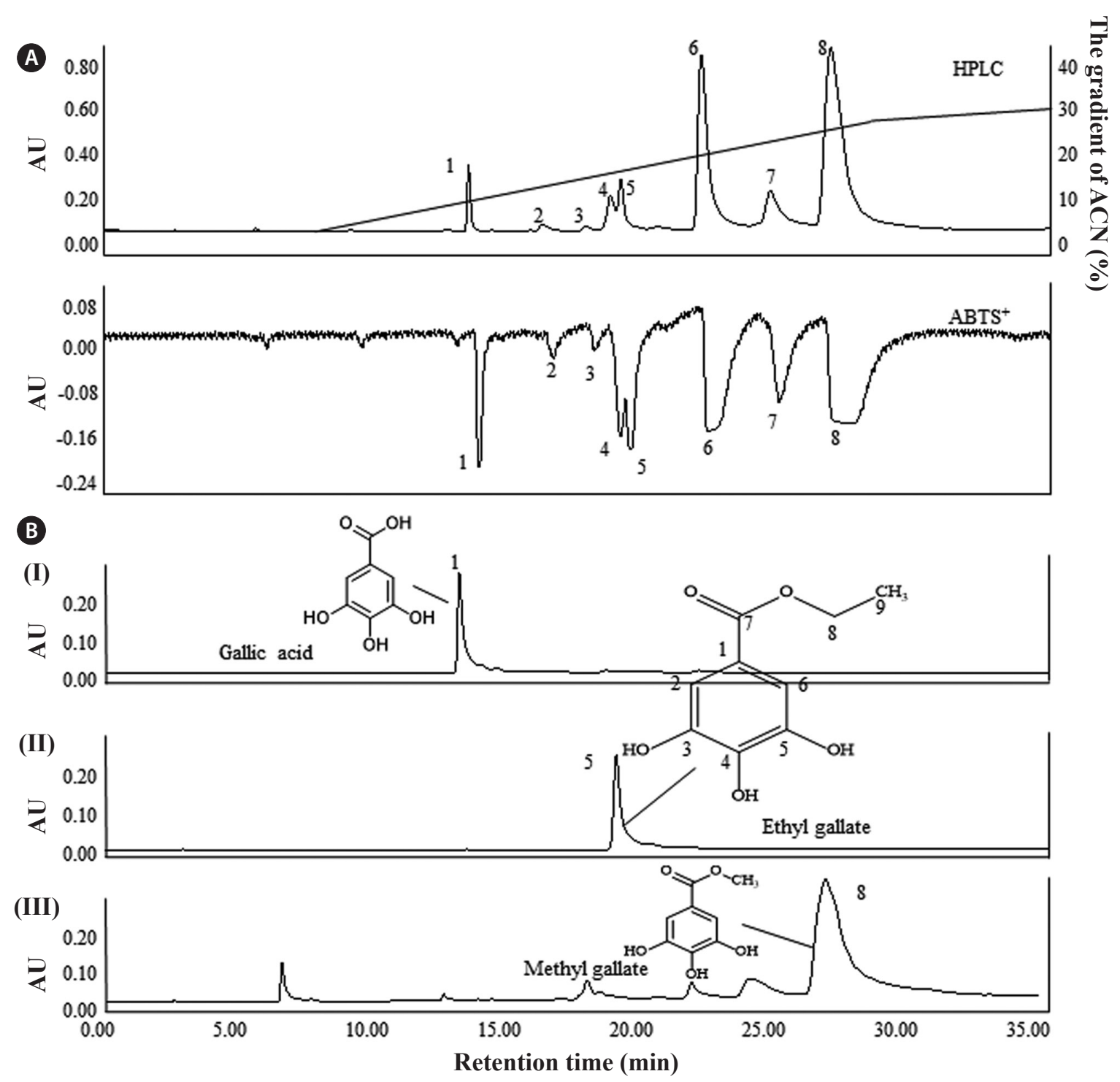

Fig. 2. Online high-performance liquid chromatography (HPLC)-ABTS analysis of ethyl acetate fraction of $70 \%$ ethanol extracts of Spirogyra sp. (A) and its active peaks collected from preparative centrifugal partition chromatography (B). Column: SunFire $5-\mu m$ ODS column $(4.6 \times 250 \mathrm{~mm}$ i.d.); mobile phase: acetonitrile-distilled water solvent system; flow rate $1.0 \mathrm{~mL} \mathrm{~min}^{-1}$; detected wave length was $290 \mathrm{~nm}$. ACN, acetonitrile.

\section{Online HPLC-ABTS analysis of SPEE}

Online HPLC-ABTS analysis, utilizing parallel chemical-detection methods, simultaneously separated and quantified the active peaks. The online analysis of SPEE exhibited 8 main peaks at the wavelength of $290 \mathrm{~nm}$, corresponding to 8 ABTS radical scavenging peaks (Fig. 2A).

The online HPLC-ABTS data were assessed from the point that the area under the negative peak producing antiradical chromatogram (obtained at $680 \mathrm{~nm}$ ) could show the total antiradical capacity of the sample analyzed. The areas of chromatograms at $680 \mathrm{~nm}$ were integrated for the 0-35 min time range to express total activity. Comparing
Table 1. The yield and total phenolic content of SPE and its fractions

\begin{tabular}{lcc}
\hline Sample & $\begin{array}{c}\text { Yield } \\
\text { (obtained sample } \\
\text { weight, mg) }\end{array}$ & $\begin{array}{c}\text { Phenolic content } \\
\text { ( } \text { ( g g }^{-1} \text { GAE) }\end{array}$ \\
\hline SPE & 1,920 & $260.47 \pm 5.21$ \\
SPEH & 37.5 & $74.42 \pm 7.82$ \\
SPEC & 154.3 & $175.74 \pm 0.00$ \\
SPEE & 524.6 & $774.42 \pm 2.61$ \\
SPEW & $1,166.0$ & $70.74 \pm 2.61$ \\
\hline
\end{tabular}

Experiments were performed in triplicate and the data are expressed as mean \pm standard error.

GAE, gallic acid equivalent; SPE, 70\% ethanol extracts of Spirogyra sp:; SPEH, hexane fraction of SPE; SPEC, chloroform fraction of SPE; SPEE, ethyl acetate fraction of SPE; SPEW, water fraction of SPE. 


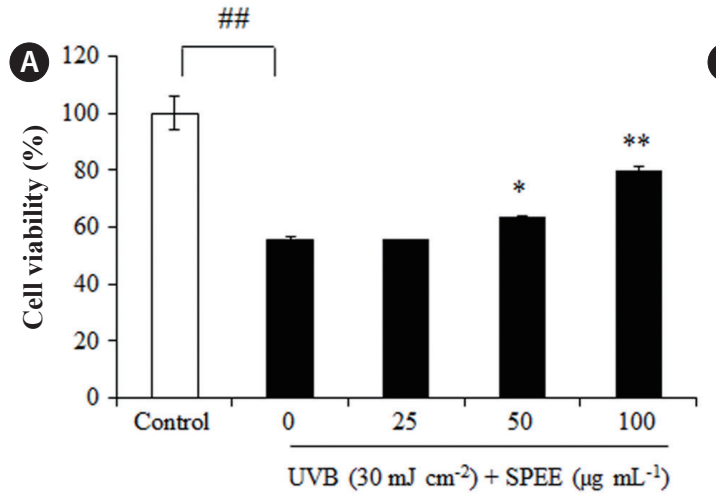

B
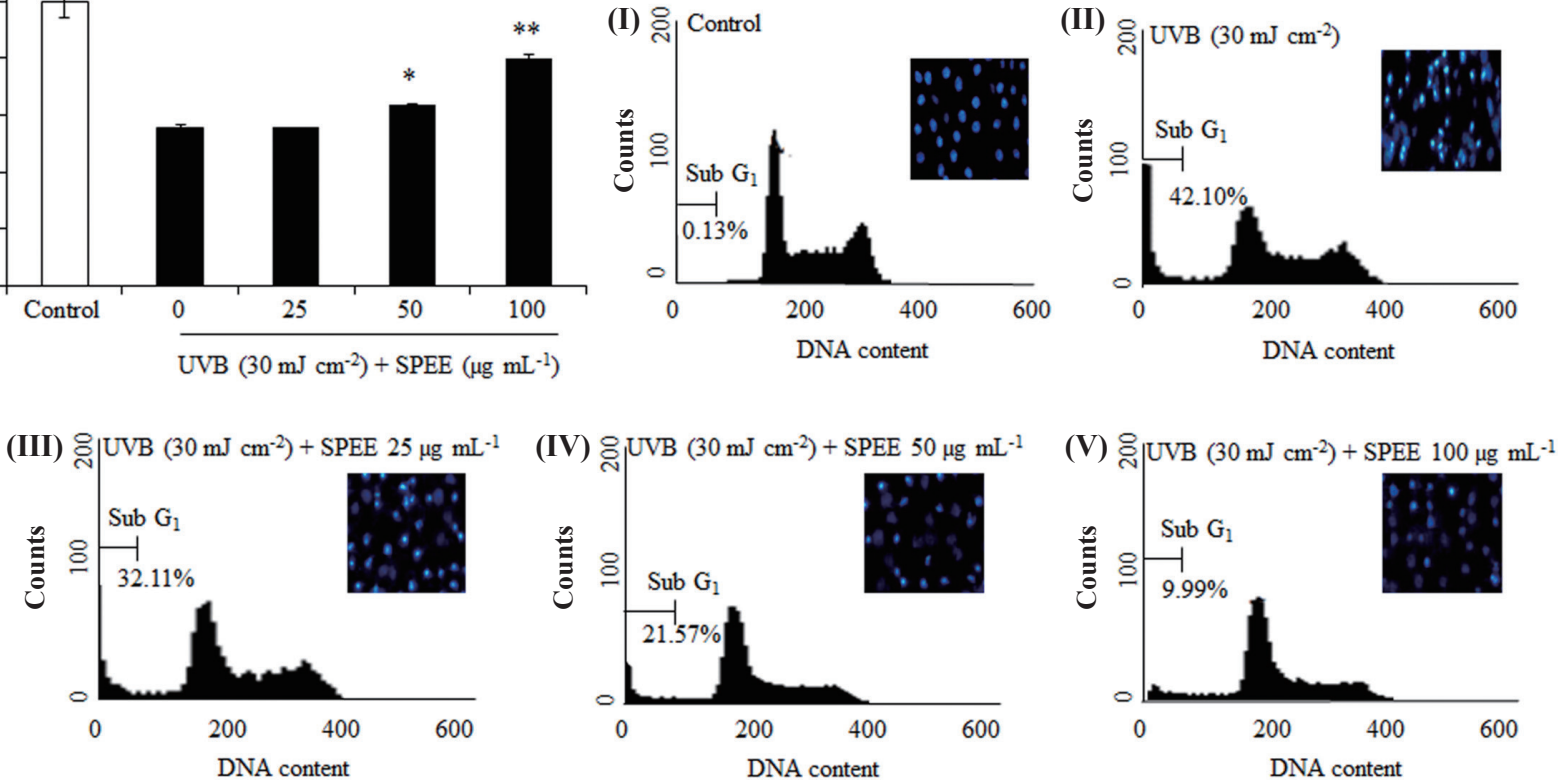

Fig. 3. Protective effects of ethyl acetate fraction of $70 \%$ ethanol extracts of Spirogyra sp. (SPEE) against cell damage by ultraviolet B (UVB) irradiation in $\mathrm{HaCaT}$ cells. (A) Cell viability as determined by MTT assay. (B) Apoptotic body formation under UVB irradiation. For apoptotic body formation analysis, cells were stained with Hoechst 33342, and nuclear morphology of cells was examined by fluorescence microscope (Olympus, Tokyo, Japan). Cell cycle analysis was conducted with FACS Calibur flow cytometer. Experiments were performed in triplicate and the data are expressed as mean \pm standard error. Means with different superscript are significantly different $\left({ }^{*} p<0.05\right.$ and $\left.{ }^{* *} p<0.01\right)$. ${ }^{* \#}$ Significantly different with control $(p<0.01)$.
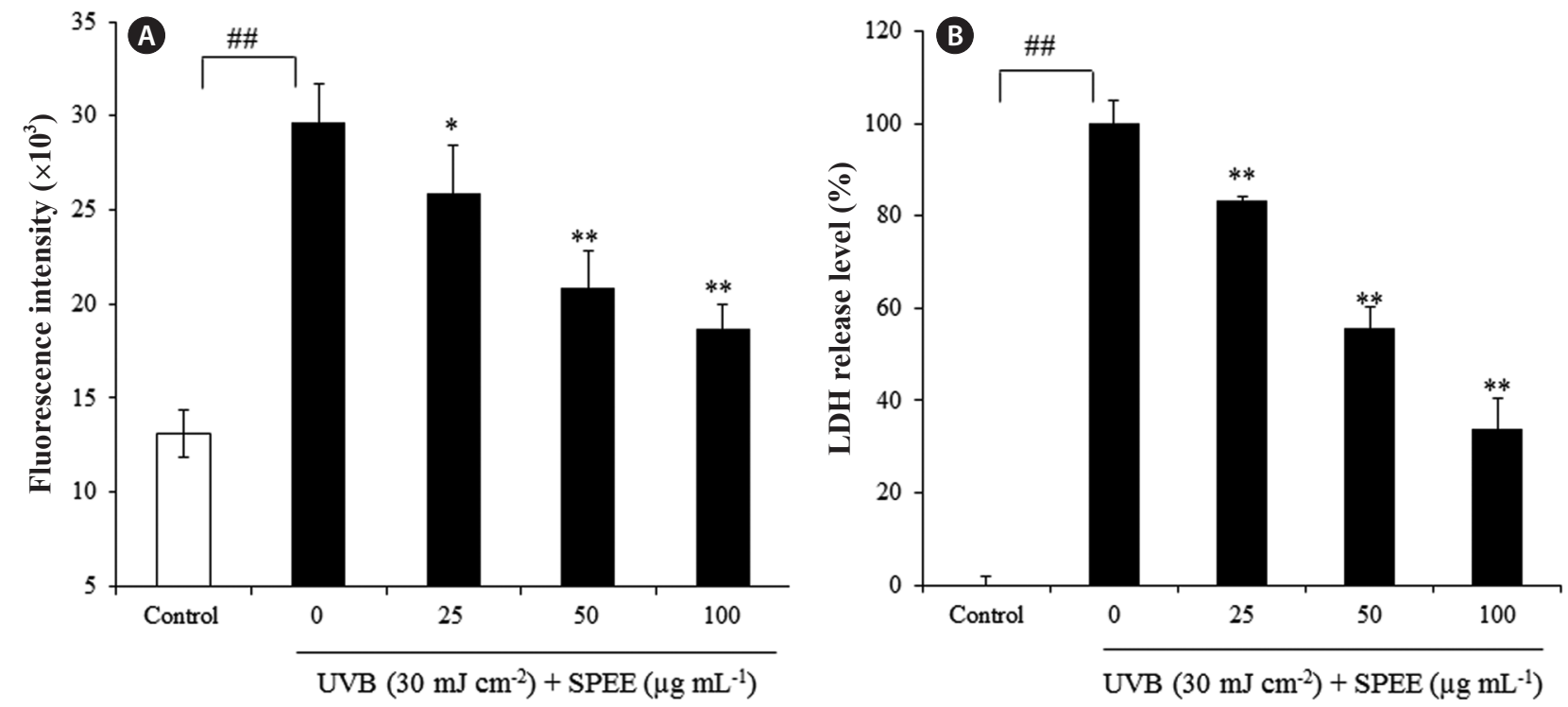

Fig. 4. Reductive effects of ethyl acetate fraction of $70 \%$ ethanol extracts of Spirogyra sp. (SPEE) on cellular reactive oxygen species (ROS) generation and lactate dehydrogenase (LDH) release induced by ultraviolet B (UVB) irradiation in HaCaT cells. Cellular ROS level was determined by DCF-DA analysis (A) and the cell damage degree was determined by LDH assay (B). Experiments were performed in triplicate and the data are expressed as mean \pm standard error. Means with different superscript are significantly different $\left({ }^{*} p<0.05\right.$ and $\left.{ }^{* *} p<0.01\right)$. ${ }^{\# *}$ Significantly different with control $(p<0.01)$. 
A

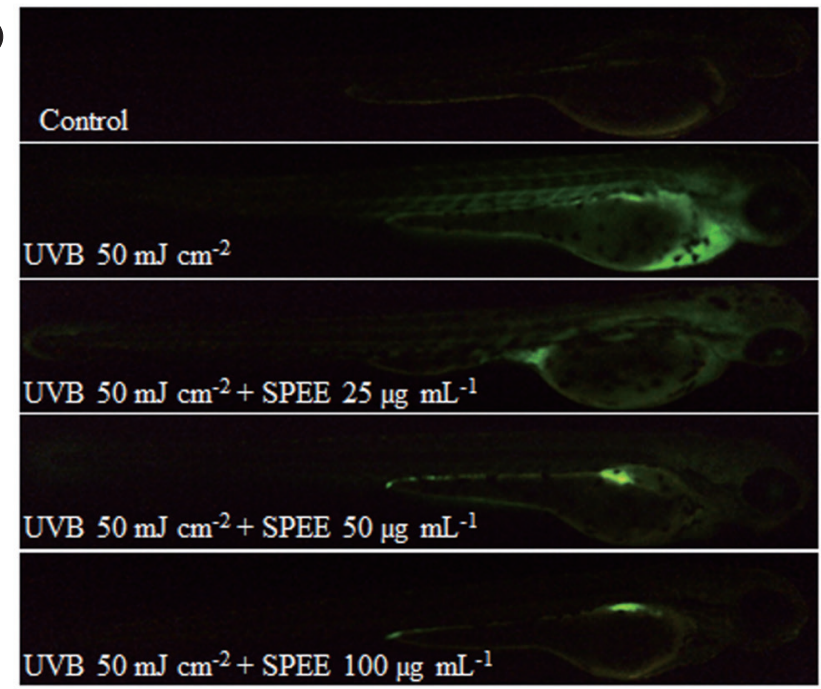

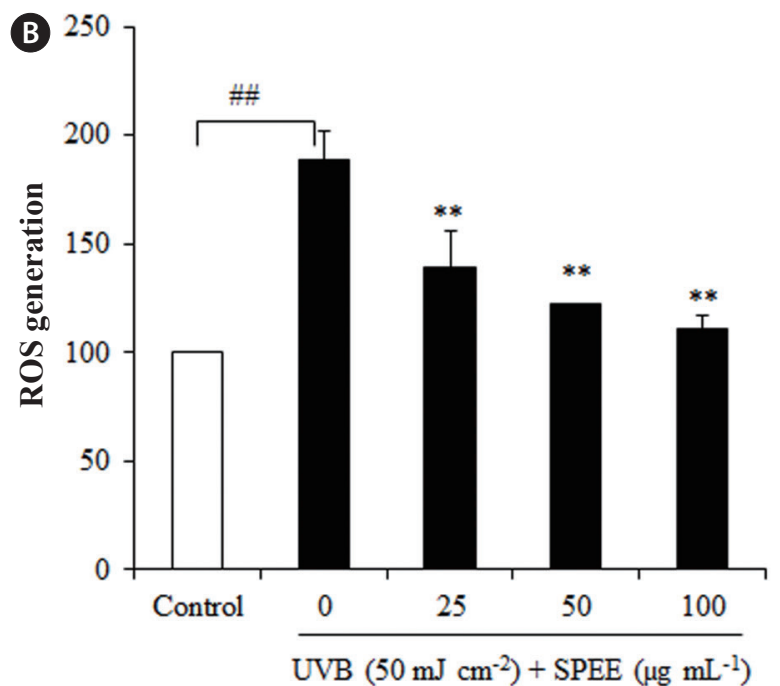

Fig. 5. Reductive effect of ethyl acetate fraction of 70\% ethanol extracts of Spirogyra sp. (SPEE) on ultraviolet B (UVB)-induced reactive oxygen species (ROS) generation in zebrafish. Zebrafish embryos at 2 days post-fertilization (dpf) were used for the anti-UVB study. At $2 \mathrm{dpf}$, the embryos were treated with SPEE. After $1 \mathrm{~h}$, the embryos were exposed to UVB $\left(50 \mathrm{~mJ} \mathrm{~cm}{ }^{-2}\right)$ per individual. The embryos were then treated with DCFH-DA solution $\left(20 \mathrm{~g} \mathrm{~mL} \mathrm{~m}^{-1}\right)$ and incubated for $1 \mathrm{~h}$ in the dark at $28.5^{\circ} \mathrm{C}$. The anesthetized embryos were photographed under a fluorescence microscope. The individual zebrafish larvae fluorescence intensity was quantified using an image J program. The photograph under the fluorescence microscope (A), and the level of ROS generation in zebrafish (B). Experiments were performed in triplicate and the data are expressed as mean \pm standard error. Means with different superscript are significantly different $\left({ }^{* *} p<0.01\right)$. ${ }^{\# \#}$ Significantly different with control $(p<0.01)$.

the antiradical capacity of different peaks, $70 \%$ or above of total antiradical activity of the individual peaks were determined as 1, 5, and 8 peaks with higher on-line antioxidant activities. Peaks showing higher antiradical activities were identified as gallic acid, ethyl gallate, and methyl gallate at $\mathrm{CPC}$ chromatogram (Fig. 2B). In particular, ethyl gallate $\left(\mathrm{C}_{9} \mathrm{H}_{10} \mathrm{O}_{2}, 198.17 \mathrm{~g} \mathrm{~mol}^{-1}\right)$ was a newly identified and isolated compound from Spirogyra sp., given the details of ${ }^{1} \mathrm{H}$ and ${ }^{13} \mathrm{C}$-NMR (see Supplementary Table S1).

\section{Protective effects of SPEE against UVB-induced apoptosis in $\mathrm{HaCaT}$ cells}

The protective effects of SPEE on the damaged HaCaT cells induced by UVB irradiation were examined by MTT assay. Cells were treated with SPEE $\left(25-100 \mu \mathrm{gL}^{-1}\right)$ and exposed to $30 \mathrm{~mJ} \mathrm{~cm}^{-2}$ of UVB. Cells that were exposed to UVB showed $44.64 \%$ less viability compared with nonUVB irradiated cells (Fig. 3A). Treatment of cells with increasing concentrations $\left(25,50\right.$, and $\left.100 \mu \mathrm{g} \mathrm{mL}^{-1}\right)$ of SPEE prior to UVB exposure, enhanced cell viability by respectively $0.32,8.22$, and $23.33 \%$. To assess the effect of SPEE on UVB-induced apoptosis of HaCaT cells, the amount of sub- $\mathrm{G}_{1}$ cells and apoptotic cells were analyzed using flow cytometry. As shown in Fig. 3B, treatment of HaCaT cells with SPEE $\left(25,50\right.$, and $\left.100 \mathrm{mg} \mathrm{mL}^{-1}\right)$ resulted in a decrease in the accumulation of cells in the sub- $\mathrm{G}_{1}$ phase by $9.99,20.53$, and $32.11 \%$, respectively. Furthermore, direct observation by Hoechst staining revealed that nuclei with chromatin condensation, apoptotic bodies and widespread membrane blebbing were formed in cells that were exposed to UVB (Fig. 3B, cell images) and this was attenuated with SPEE treatment in a concentration dependent manner. This data suggested that SPEE treatment reduced UVB-induced apoptosis of HaCaT cells.

\section{SPEE reduces UVB-induced cellular ROS genera- tion and $\mathrm{LDH}$ release in $\mathrm{HaCaT}$ cells}

To assess the effect of SPEE on the oxidative stress induced by $30 \mathrm{~mJ} \mathrm{~cm}^{-2}$ of UVB in HaCaT cells, intracellular ROS levels were determined by measuring the intracellular oxidation of 2,7-dichlorodihydrofluorescein $\left(\mathrm{DCFH}_{2}\right)$. Exposure of $\mathrm{DCFH}_{2}$ loaded HaCaT cells to UVB, induced oxidative stress as assessed by DCF formation indicating the production of ROS (Fig. 4A). Treatment of cells with increasing concentrations of SPEE, protected cells from UVB-induced oxidative stress in a concentration-dependent manner.

$\mathrm{LDH}$ release as an indicative of cellular damage was 
also assessed. Cells exposed to UVB showed a significant increase in the level of LDH release, compared to nonUVB-exposed cells $(\mathrm{p}<0.01)$ (Fig. 4B). The increased LDH release levels in UVB-exposed cells were reduced by $35.98 \%$ with $100 \mu \mathrm{g} \mathrm{mL}^{-1}$ of SPEE treatment $(\mathrm{p}<0.01)$ (Fig. $4 \mathrm{~B})$.

\section{SPEE reduces ROS generation induced by UVB irradiation in zebrafish}

The protective effect of SPEE on the damage induced by UVB was further assessed in in vivo model of zebrafish. Fish were treated with SPEE (25-100 $\left.\mu \mathrm{g} \mathrm{mL}^{-1}\right)$ and exposed to $50 \mathrm{~mJ} \mathrm{~cm}^{-2}$ of UVB. Fig. 5A shows a typical fluorescence micrograph of a zebrafish. The control group, which was subjected to neither UVB nor SPEE, generated no fluorescence, whereas the group that was exposed to UVB, generated DCF fluorescence, suggesting an increase in the level of ROS by UVB irradiation in the zebrafish. However, when the zebrafish were treated with the different concentrations of SPEE prior to UVB exposure; a concentration-dependent reduction in the generation of ROS was observed (Fig. 5A \& B). These results suggest a protective effect of SPEE against oxidative stress induced by UVB exposure in in vivo zebrafish model.

\section{DISCUSSION}

Exposure of cells to UVB radiation can result in an increased ROS generation, which is responsible for skin cancer development and photoaging (Raut et al. 2012). As ROS are implicated in skin damage by UVB, scavenging of these species could prevent the oxidative reactions and subsequently protect skin from the damaging effects of UVB (Masaki 2010, Kammeyer and Luiten 2015).

The phenolic phytochemicals from botanical antioxidants have been widely used for their ability to delay the process of photoaging by reducing the harmful effects of UV radiation through scavenging ROS (Heo et al. 2009, Ko et al. 2011, Ryu et al. 2015). Heo et al. (2010) reported diphlorethohydroxycarmalol isolated from Ishige okamurae showing strong protective effects against UVBinduced human fibroblast cell damage (Heo et al. 2010). Yang et al. evaluated the effects of quercetin against UVB-induced cell death in in vitro HaCaT cells and in vivo zebrafish model (Yang et al. 2012). This present work suggests the protective effects of SPEE against oxidative stress induced by UVB in in-vitro and in-vivo models.
Through serial fractionations of SPE, the gallic acid derivatives (SPEE) (Table 1) showing $774.42 \pm 2.61 \mathrm{mg} \mathrm{g}^{-1}$ GAE was selected and analyzed in on-line HPLC-ABTS chromatogram at $680 \mathrm{~nm}$, which is the specific wavelength for polyphenols reacting with the radical scavengers. Furthermore, the peaks derived from SPEE showing $70 \%$ or above of total antiradical activity were identified as gallic acid, ethyl gallate, and methyl gallate (Fig. 2B).

We evaluated the protective activity of SPEE on UVBinduced damage in HaCaT cells. The results in the study showed a protective effect of SPEE against reduction in cell viability caused by UVB irradiation. This observation was further studied for the protective effect of SPEE on UVB-induced apoptosis using flow cytometer and propidium iodide staining. The UVB-induced accumulation of cells in the sub- $\mathrm{G}_{1}$ phase was significantly decreased with SPEE pre-treatment in HaCaT cells, suggesting the protective effects of SPEE against sub- $G_{1}$ cell cycle arrest, and apoptosis.

UVB-mediated apoptosis was also associated with an increase in the intracellular ROS levels, suggesting an activation of ROS-producing enzymes or impairment of the antioxidant pool which may predispose cells to lower defense against oxidative stress (Masaki 2010, Raut et al. 2012). To evaluate the activity of SPEE on the UVBinduced oxidative stress in HaCaT cells, we assessed the levels of ROS and LDH release with or without SPEE treatment. Treatment with SPEE prior to UVB exposure resulted in considerable protection of $\mathrm{HaCaT}$ cells against ROS generation and LDH release. We further examined the effect of SPEE against oxidative stress in in vivo zebrafish model. UVB exposure induced ROS generation in zebrafish, which was inhibited by treatment with SPEE. Collectively, these results suggested that SPEE reduced apoptosis induced by UVB via inhibiting ROS levels in HaCaT cells and zebrafish.

In conclusion, four main objectives in this study were achieved: (1) enhancement of phenolic content of Spirogyra sp. by serial fractionation, (2) determination of the radical scavenging activity of gallic acid derivatives of Spirogyra sp. (SPEE) based on on-line HPLC-ABTS, (3) separation of gallic acid, methyl gallate, and ethyl gallate from SPEE in CPC chromatogram. Among these compounds, ethyl gallate is isolated from Spirogyra sp. for the first time, and (4) examination of the protective effect of SPEE treatment prior to UVB exposure in in vitro HaCaT cells and in vivo zebrafish. This study may provide insight into the potential use of gallic acid derivatives from Spirogyra sp. for the treatment of skin damage caused by UVB. 


\section{SUPPLEMENTARY MATERIAL}

Supplementary Table S1. The nuclear magnetic resonance spectroscopic data of ethyl gallate (http://www.ealgae.org).

\section{ACKNOWLEDGEMENTS}

This research was financially supported by Basic Science Research Program through the National Research Foundation of Korea (NRF) funded by the Ministry of Education, Science and Technology (2013R1A1A2064909).

\section{REFERENCES}

Alves, G. d. A. D., de Souza, R. O., Rogez, H., Masaki, H. \& Fonseca, M. J. V. 2016. Cecropia obtusa, an Amazonian ethanolic extract, exhibits photochemoprotective effect in vitro and balances the redox cellular state in response to UV radiation. Ind. Crops Prod. 94:893-902.

Bishnoi, N. R., Bajaj, M. \& Sanatomba, K. 2005. Biosorption of zinc (II) using Spirogyra species from electroplating effluent. J. Environ. Biol. 26:661-664.

Chandler, S. F. \& Dodds, J. H. 1983. The effect of phosphate, nitrogen and sucrose on the production of phenolics and solasodine in callus cultures of Solanum laciniatum. Plant Cell Rep. 2:205-208.

Dong, Q., Svoboda, K., Tiersch, T. R. \& Monroe, W. T. 2007. Photobiological effects of UVA and UVB light in zebrafish embryos: evidence for a competent photorepair system. J. Photochem. Photobiol. B Biol. 88:137-146.

Eshaq, F. S., Ali, M. N. \& Mohd, M. K. 2010. Spirogyra biomass a renewable source for biofuel (bioethanol) production. Int. J. Eng. Sci. Technol. 2:7045-7054.

Farooqi, A. A., Li, R. -N., Huang, H. -W., Ismail, M., Yuan, S. -S. F., Wang, H. -M. D., Liu, J. -R., Tang, J. -Y. \& Chang, H. -W. 2015. Natural products mediated regulation of oxidative stress and DNA damage in ultraviolet exposed skin cells. Curr. Pharm. Biotechnol. 16:1078-1084.

Fernando, I. P. S., Kim, H. -S., Sanjeewa, K. K. A., Oh, J. -Y., Jeon, Y. -J. \& Lee, W. W. 2017a. Inhibition of inflammatory responses elicited by urban fine dust particles in keratinocytes and macrophages by diphlorethohydroxycarmalol isolated from a brown alga Ishige okamurae. Algae 32:261-273.

Fernando, I. P. S., Sanjeewa, K. K. A., Samarakoon, K. W., Lee, W. W., Kim, H. -S., Kim, E. -A., Gunasekara, U. K. D. S. S., Abeytunga, D. T. U., Nanayakkara, C., de Silva, E. D., Lee,
H. -S. \& Jeon, Y. -J. 2017b. FTIR characterization and antioxidant activity of water soluble crude polysaccharides of Sri Lankan marine algae. Algae 32:75-86.

Gill, S. S. \& Tuteja, N. 2010. Reactive oxygen species and antioxidant machinery in abiotic stress tolerance in crop plants. Plant Physiol. Biochem. 48:909-930.

Gupta, V. K. \& Rastogi, A. 2008. Biosorption of lead from aqueous solutions by green algae Spirogyra species: kinetics and equilibrium studies. J. Hazard. Mater. 152:407-414.

Gupta, V. K., Rastogi, A., Saini, V. K. \& Jain, N. 2006. Biosorption of copper (II) from aqueous solutions by Spirogyra species. J. Colloid Interface Sci. 296:59-63.

Gupta, V. K., Shrivastava, A. K. \& Jain, N. 2001. Biosorption of chromium (VI) from aqueous solutions by green algae Spirogyra species. Water Res. 35:4079-4085.

Heo, S. -J., Ko, S. -C., Cha, S. -H., Kang, D. -H., Park, H. -S., Choi, Y. -U., Kim, D., Jung, W. -K. \& Jeon, Y. -J. 2009. Effect of phlorotannins isolated from Ecklonia cava on melanogenesis and their protective effect against photo-oxidative stress induced by UV-B radiation. Toxicol in Vitro 23:1123-1130.

Heo, S. -J., Ko, S. -C., Kang, S. -M., Cha, S. -H., Lee, S. -H., Kang, D. -H., Jung, W. -K., Affan, A., Oh, C. \& Jeon, Y. -J. 2010. Inhibitory effect of diphlorethohydroxycarmalol on melanogenesis and its protective effect against UV-B radiation-induced cell damage. Food Chem. Toxicol. 48:1355-1361.

Hwang, J. -H., Kim, K. -J., Ryu, S. -J. \& Lee, B. -Y. 2016. Caffeine prevents LPS-induced inflammatory responses in RAW264.7 cells and zebrafish. Chem. Biol. Interact. 248:1-7.

Kammeyer, A. \& Luiten, R. M. 2015. Oxidation events and skin aging. Ageing Res. Rev. 21:16-29.

Kang, M. -C., Kim, S. Y., Kim, Y. T., Kim, E. -A., Lee, S. -H., Ko, S. -C., Wijesinghe, W. A. J. P., Samarakoon, K. W., Kim, Y. -S., Cho, J. H., Jang, H. -S. \& Jeon, Y. -J. 2014. In vitro and in vivo antioxidant activities of polysaccharide purified from aloe vera (Aloe barbadensis) gel. Carbohydr. Polym. 99:365-371.

Kang, N., Lee, J. -H., Lee, W., Ko, J. -Y., Kim, E. -A., Kim, J. -S., Heu, M. -S., Kim, G. H. \& Jeon, Y. -J. 2015. Gallic acid isolated from Spirogyra sp. improves cardiovascular disease through a vasorelaxant and antihypertensive effect. Environ. Toxicol. Pharmacol. 39:764-772.

Kim, H. -S., Zhang, C., Lee, J. -H., Ko, J. -Y., Kim, E. -A., Kang, N. \& Jeon, Y. -J. 2014. Evaluation of the biological activities of marine bacteria collected from Jeju Island, Korea, and isolation of active compounds from their secondary metabolites. Fish Aquat. Sci. 17:215-222.

Kim, J. -K., Kim, Y., Na, K. -M., Surh, Y. -J. \& Kim, T. -Y. 2007. 
[6]-Gingerol prevents UVB-induced ROS production and COX-2 expression in vitro and in vivo. Free Radic. Res. 41:603-614.

Ko, S. -C., Cha, S. -H., Heo, S. -J., Lee, S. -H., Kang, S. -M. \& Jeon, Y. -J. 2011. Protective effect of Ecklonia cava on UVB-induced oxidative stress: in vitro and in vivo zebrafish model. J. Appl. Phycol. 23:697-708.

Kong, S. -Z., Chen, H. -M., Yu, X. -T., Zhang, X., Feng, X. -X., Kang, X. -H., Li, W. -J., Huang, N., Luo, H. \& Su, Z. -R.

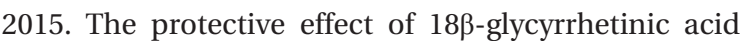
against UV irradiation induced photoaging in mice. Exp. Gerontol. 61:147-155.

Kulms, D. \& Schwarz, T. 2002. Mechanisms of UV-induced signal transduction. J. Dermatol. 29:189-196.

Lee, J. -H., Han, J. W., Ko, J. -Y., Lee, W., Ahn, G., Kim, C. -Y., Kim, G. H. \& Jeon, Y. -J. 2015a. Protective effect of a freshwater alga, Spirogyra sp., against lipid peroxidation in vivo zebrafish and purification of antioxidative compounds using preparative centrifugal partition chromatography. J. Appl. Physiol. 28:181-189.

Lee, J. -H., Ko, J. -Y., Oh, J. -Y., Kim, E. -A., Kim, C. -Y. \& Jeon, Y. -J. 2015b. Evaluation of phlorofucofuroeckol-A isolated from Ecklonia cava (Phaeophyta) on anti-lipid peroxidation in vitro and in vivo. Algae 30:313-323.

Lee, J. -H., Zhang, C., Ko, J. -Y., Lee, J. -S. \& Jeon, Y. -J. 2015c. Evaluation on anticancer effect against HL-60 cells and toxicity in vitro and in vivo of the phenethyl acetate isolated from a marine bacterium Streptomyces griseus. Fish. Aquat. Sci. 18:35-44.

Lee, S. -H., Kang, S. -M., Sok, C. H., Hong, J. T., Oh, J. -Y. \& Jeon, Y. -J. 2015d. Cellular activities and docking studies of eckol isolated from Ecklonia cava (Laminariales, Phaeophyceae) as potential tyrosinase inhibitor. Algae 30:163-170.

Liu, M., Li, X., Liu, Y., Shi, Y. \& Ma, X. 2015. Analysis of differentially expressed genes under UV-B radiation in the desert plant Reaumuria soongorica. Gene 574:265-272.

Masaki, H. 2010. Role of antioxidants in the skin: anti-aging effects. J. Dermatol. Sci. 58:85-90.

Mohan, S. V., Ramanaiah, S. V., Rajkumar, B. \& Sarma, P. N. 2007. Removal of fluoride from aqueous phase by biosorption onto algal biosorbent Spirogyra sp.-IO2: sorption mechanism elucidation. J. Hazard. Mater. 141:465474.
Oh, J. -Y., Fernando, I. P. S. \& Jeon, Y. -J. 2016. Potential applications of radioprotective phytochemicals from marine algae. Algae 31: 403-414.

Ramaraj, R., Unpaprom, Y., Whangchai, N. \& Dussadee, N. 2015. Culture of macroalgae Spirogyra ellipsospora for long-term experiments, stock maintenance and biogas production. Emerg. Life Sci. Res. 1:38-45.

Raut, S., Bhadoriya, S. S., Uplanchiwar, V., Mishra, V., Gahane, A. \& Jain, S. K. 2012. Lecithin organogel: a unique micellar system for the delivery of bioactive agents in the treatment of skin aging. Acta Pharm. Sin. B 2:8-15.

Rezvani, H. R., Mazurier, F., Cario-André, M., Pain, C., Ged, C., Taïeb, A. \& de Verneuil, H. 2006. Protective effects of catalase overexpression on UVB-induced apoptosis in normal human keratinocytes. J. Biol. Chem. 281:1799918007.

Ryu, B., Ahn, B. -N., Kang, K. -H., Kim, Y. -S., Li, Y. -X., Kong, C. -S., Kim, S. -K. \& Kim, D. G. 2015. Dioxinodehydroeckol protects human keratinocyte cells from UVB-induced apoptosis modulated by related genes Bax/Bcl-2 and caspase pathway. J. Photochem. Photobiol. B Biol. 153:352-357.

Samarakoon, K. W., Cha, S. -H., Lee, J. -H. \& Jeon, Y. -J. 2013. The growth, innate immunity and protection against $\mathrm{H}_{2} \mathrm{O}_{2}$-induced oxidative damage of a chitosan-coated diet in the olive flounder Paralichthys olivaceus. Fish. Aquat. Sci. 16:149-158.

Sanjeewa, K. K. A., Fernando, I. P. S., Samarakoon, K. W., Lakmal, H. H. C., Kim, E. -A., Kwon, O. -N., Dilshara, M. G., Lee, J. -B. \& Jeon, Y. -J. 2016. Anti-inflammatory and anticancer activities of sterol rich fraction of cultured marine microalga Nannochloropsis oculata. Algae 31:277287.

Wijesinghe, W. A. J. P., Jeon, Y. J., Ramasamy, P., Wahid, M. E. A. \& Vairappan, C. S. 2013. Anticancer activity and mediation of apoptosis in human HL-60 leukaemia cells by edible sea cucumber (Holothuria edulis) extract. Food Chem. 139:326-331.

Yang, H. -M., Ham, Y. -M., Yoon, W. -J., Roh, S. W., Jeon, Y. -J., Oda, T., Kang, S. -M., Kang, M. -C., Kim, E. -A., Kim, D. \& Kim, K. -N. 2012. Quercitrin protects against ultraviolet B-induced cell death in vitro and in an in vivo zebrafish model. J. Photochem. Photobiol. B Biol. 114:126-131. 